The Digital Object Identifier - DOI: 10.37952/ROI-jbc-01/20-64-12-88

Submitted on December 23, 2020.

\title{
Criminological prognostication of the emergence of new types of narcotic drugs
}

\author{
(C) Ilya V. Shlykov, ${ }^{+}$Alexey E. Kovalenko, and Maria V. Rushakova \\ Federal State Budgetary Educational Institution of Higher Education. Dmitry Mendeleev \\ University of Chemical Technology of Russia. Miusskaya square, 9. Moscow, 125047. Russia. \\ E-mail: ilyashlykov@muctr.ru
}

\begin{abstract}
*Supervising author; ${ }^{+}$Corresponding author
Keywords: forensic forecasting of new types of drugs, new psychoactive substances (NPS), new psychoactive substances (NPS), designer drugs.
\end{abstract}

\begin{abstract}
The article presents the results of studying the algorithms for the emergence of new types of narcotic drugs, identifies the patterns of changes in the chemical structures of new psychoactive substances, and proposes a mechanism for criminological prognostication of the emergence of new types of substances with

Analytical studies of the emergence of new psychostimulants have confirmed the correctness of the chosen model of state control of new psychoactive substances - the introduction of "derivative narcotic substances and psychotropic substances" into Russian legislation.

An objective and comprehensive study of the chemical structures of molecules of new psychoactive substances also confirmed the legitimacy of establishing state control over the illegal traffic of analogues of narcotic drugs and psychotropic substances.

In general, the conducted analytical study suggests considering from the scientific and analytical point of view the possible introduction into law enforcement practice of a new direction "Criminological prognostication of the emergence of new types of narcotic drugs".

The general algorithms and patterns found in the process of analytical research in the new structures of molecules of psychoactive substances have confirmed both the forensic search and the logical and stepwise development of science in the field of psychoactive substances.
\end{abstract} narcogenic potential.

\section{References}

[1] V.V. Mrykhin, A.V. Atsyborov. Designer drugs: a short history, an attempt at systematization using the example of "spice" and "salt" (review). Interactive Science. The Medicine. 2017. No.11. P.36-39. (russian)

[2] O.N. Korchagin, D.K. Chirkov, A.S. Litvinenko. Synthetic drugs in Russia as a real threat to national security. Actual Problems of Economics and Law. 2015. Vol.33. No.1. P.245-253. (russian)

[3] I. Shlykov. The Psychogenic storm of special purpose. Person and Law. 2015. No.11. P.29-34. (russian)

[4] N.V. Kudril. Topical issues of toxicology and laboratory identification of synthetic cannabinoids (prepared based on the materials of the European Monitoring Center for Drugs and Drug Addiction EMCDDA). Emergency Medicine. 2015. Vol.65. No.2. P.9-18. (russian)

[5] A. Shrivastava, Ak. Chakraborty, N. Umpanyu, and A. Singh. Recent progress in Chemistry and Biology of Indazole and its Derivates: a brief review. Austin Journal of Analytical and Pharmaceutical Chemistry. 2016. Vol.3. Iss.4. P.1-23.

[6] V.V. Gladyrev, M.A. Drozdov, D.N. Kedys, V.N. Latygin, V.P. Melkozerov, L.I. Modinova, R.A. Puzov, I.I. Sarychev, A.V. Toritsin, M.I. Chagarova, V.A. Shevyrin. Expert study of smoking blends containing the most common synthetic cannabinoids. Guidelines. EKTs Ministry of Internal Affairs of Russia. 2010. P.60. (russian)

[7] Decree of the Government of the Russian Federation. No. 681 of June 30, 1998 "On approval of the list of narcotic drugs, psychotropic substances and precursors subject to control on the territory of the Russian Federation" (with amendments and additions). (russian)

[8] EMCDDA initial report on the new psychoactive substance methyl 2-(\{[1-(4-fluorobutyl)-1H-indol-3yl]carbonyl \}amino)-3,3-dimethylbutanoate (4F-MDMB-BICA). EMCDDA. 2020. (russian) 